\title{
Surveillance of adverse events following immunization in Oman, 2006-2015
}

Prakash K. Patel ${ }^{1}$, Bader Al-Rawahi ${ }^{1}$, Athari Al-Jawari ${ }^{1}$, Idris Al-Abaidani ${ }^{1}$ and Seif Al-Abri ${ }^{2}$

${ }^{1}$ Department of Communicable Diseases, Directorate General for Disease Surveillance and Control, Ministry of Health, Muscat, Oman. (Correspondence to: Prakash K. Patel: drprakashkp@gmail.com). ${ }^{2}$ Directorate General for Disease Surveillance and Control, Ministry of Health, Muscat, Oman.

\begin{abstract}
Background: In 1996, Oman launched its surveillance programme for adverse events following immunization (AEFI) to address vaccine safety concerns. In 2010, an analysis of surveillance activities for AEFI was done for 10 years (1996-2005).

Objectives: The main objective of the study was to describe the trend of AEFI over the 10-year period, 2006-2015, and compare the findings with a previous report in Oman and reports from other countries.
\end{abstract}

Methods: A descriptive record-based review of AEFI was carried out using the national AEFI surveillance database for the study period, 2006-2015.

Results: A total of 890 adverse event reports were received, giving an annual rate during the review period of 21.4 per 100000 population or 8.3 per 100 ooo doses administered. The most frequently reported AEFI were BCG adenitis and local reactions - 31.1 and 4.1 per 100000 doses respectively. There were no reported deaths. Pentavalent vaccine was responsible for the greatest proportion of adverse events $(30 \%)$. Local reaction was the most common adverse event among all vaccines administered. The Hexa vaccine caused fewer adverse events compared with the pentavalent vaccine, probably due to the acellular pertussis component -0.8 versus 1.5 per 100000 doses administered respectively.

Conclusion: The overall rate of AEFI (8.3 per 100 ooo doses administered) is comparable to the rate (10.8/100 ooo doses) in the previous decade (1996-2005) in Oman. The reported rates for individual vaccines are similar to or below international rates.

Keywords: AEFI, vaccine, surveillance, Oman

Citation: Patel PK; Al-Rawahi B; Al-Jawari A; Al-Abaidani I; Al-Abri S. Surveillance of adverse events following immunization in Oman, 2006-2015. East Mediterr Health J. 2018;24(2):119-126. https://doi.org/10.26719/2018.24.2.119.

Received: 27/10/16; accepted: 12/02/17

Copyright (C) World Health Organization (WHO) 2018. Some rights reserved. This work is available under the CC BY-NC-SA 3.o IGO license (https:// creativecommons.org/licenses/by-nc-sa/3.0/igo).

\section{Introduction}

Vaccines have traditionally been the most effective means to fight infectious diseases and improve global public health. Vaccination given during childhood is generally harmless. Adverse events, if any, are usually minor and self-limiting; very few are serious and potentially life-threatening. To increase immunization rates and improve the quality of services, the surveillance of adverse events following immunization (AEFI) must become an integral part of any national immunization programme.

AEFI is "any untoward medical occurrence which follows immunization and which does not necessarily have a causal relationship with the usage of the vaccine" (1). Surveillance of AEFI is an important component of any national immunization programme. In $2001,53 \%$ of all World Health Organization (WHO) member countries reported having a national AEFI monitoring system, an increase from $45 \%$ in 2000 . The proportion among the countries of the Eastern Mediterranean Region was 59\% in 2001 (2).

In the past decade, growing concerns about vaccine and immunization safety have emerged among the medical community as well as the public. To encourage countries to report AEFI with essential information, the Global Advisory Committee on Vaccine Safety (GACVS) proposed in June 2012 a set of 22 simple and vaccinespecific minimum AEFI records (core variables). This revised set of variables should enhance the quality of data collected and enable national programme managers in WHO Member States to better monitor vaccine safety (3). In 1996, Oman launched its AEFI surveillance programme to address vaccine safety concerns.

In Oman, as of 2015, 12 antigens are included in the national immunization programme for children. The vaccination coverage levels increased substantially from $10 \%$ in 1981 to over $95 \%$ in 1995 . Almost $100 \%$ coverage among eligible children has been maintained to date, which has had a considerable impact on the incidence of vaccine-preventable diseases in Oman (4). The completeness of AEFI surveillance data is nearly $95 \%$. The critical missing data are usually completed through a feedback mechanism (4). Oman has a high-quality vaccine management system; in recognition of this, WHO assigned Oman as a vaccine management training 
centre. This centre organized 2 regional training courses in 2016. WHO congratulated Oman as the first country to achieve the highest EVM score for all criteria at all levels globally.

The Oman immunization manual, with its standard operating procedures, was published by the Ministry of Health in 2003 and includes a section on AEFI describing the causes, types and surveillance-related guidelines and procedures (4). The revised manual is due for publication in 2018. It is mandatory to notify all AEFI within 24 hours as per the Ministry of Health policy. All institutions at all levels of health care that provide immunization services and 47 vaccine-qualified private clinics are included in the surveillance network. The staff in the immunization section at health care facilities are trained in the identification of events and the reporting protocol, in addition to receiving ongoing in-service training. During periodic national supervisory visits, the staff are updated on new and/or revised policies.

The main objectives of this paper was to describe the trend of AEFI, detect new, unusual or rare adverse vaccine events and identify patient risk factors for particular types of adverse event. An analysis of surveillance activities for AEFI was done for 10 years (1996-2005) in 2010 (5). The current study presents an analysis of the data on AEFI reported over 2006-2015. The study also acts as an evaluation of AEFI surveillance.

\section{Methods}

The study was a record-based descriptive study of reported AEFI events where the date of vaccination or onset of the adverse event occurred between January 2006 and December 2015.

An AEFI was defined as any adverse event that occurred after a vaccination, which might be related to the vaccine itself or to its handling or administration $(4,6,7)$. A serious adverse event following vaccination was recorded when a patient died, experienced a lifethreatening illness, required hospitalization or when the condition resulted in permanent disability.

All medical events related to vaccines, usual or unusual, minor or serious, for which medical care was sought were considered, including all cases of: Bacille Calmette-Guérin (BCG) lymphadenitis; injection site abscesses; and deaths, hospitalizations and other severe or unusual medical incidents that were thought by health workers or patients to be related to immunization. Mild episodes of fever after receiving the pentavalent vaccine or mild local pain and swelling were not required to be reported. However, any event related to vaccine safety is given precedence in terms of treatment and follow up of cases.

The following were the main vaccines studied: BCG, diphtheria-tetanus-pertussis (DTP), pentavalent (DTPHib-HBV), hexavalent (DTP-Hib-HBV-IPV), hepatitis B virus (HBV), measles-mumps-rubella (MMR), injectable polio vaccine (IPV), pneumococcal conjugate vaccine (PCV-7, 10, 13), varicella, influenza, diphtheria-tetanus
(DT) and tetanus toxoid (TT).

The data were collected by the Expanded Programme of Immunization section of the Ministry of Health and compiled and analysed on a monthly basis by the Department of Communicable Diseases. The modified WHO recommended reporting form with standard case definitions was used (6). Regular feedback was given through monthly reports for follow-up and action. A compiled report was submitted to the WHO Regional Office for the Eastern Mediterranean at the end of every quarter. All serious events as well as clusters of events were investigated within a reasonable timeframe.

\section{Data analysis}

The data were compiled in Microsoft Excel format and data analysis was performed using SPSS, version 17.0. Average annual population-based rates of AEFI were calculated for different variables using the estimated population for each year based on 2003 census data (https:// ncsi.gov.om/). Dose-related AEFI rates were calculated by using the number of doses administered from the national database as the denominator. Relative risk (RR) and $95 \%$ confidence intervals (CI) were calculated using the national average as the reference. A P-value $<0.05$ was considered statistically significant.

\section{Ethical approval}

Ethical approval for the study was not deemed necessary because it was a records-based study and there was no direct intervention involvement with patients.

\section{Results}

A total of 890 AEFI reports were received during the period 2006-2015 from a total of 10749013 vaccine doses administered. The overall reporting rate for this period was therefore 8.3 per 100000 doses administered or 21.4 per 100000 population (based on the 2014-2015 population estimate). The annual AEFI reporting rates ranged from 5.4 to 12.3 per 100000 doses during the study period. The highest rate was observed in 2007 while the lowest was in 2012 (Figure 1).

Table 1 shows the data by age, gender and governorate. The highest proportion of adverse events was among children aged $<1$ year $(73.8 \%)$, compared with those aged $1-2$ years $(14.3 \%)$ and $>2$ years $(11.9 \%)$. The reporting rate per 100000 doses administered was significantly higher among those aged $<1$ year (9.3/100 ooo doses) compared with the national average (8.3/100 ooo doses) $(R R=1.5$, 95\% CI: $1.3-1.7$, P < 0.001).

A marginally higher proportion of AEFI reports were from males than females (50.9\% versus $49.1 \%$ ). However, the reporting rate per 100000 doses administered was significantly higher among females than males (9.6/100 ooo doses versus 7.3/100 ooo doses) $(R R=1.3,95 \%$ CI: $1.2-1.5, P<0.001)$.

The distribution of AEFI reports by province (regions/ governorates) indicated that 3 regions had significantly higher rates of adverse event reports per 100000 doses administered compared with the national average: 


\begin{tabular}{|c|c|c|c|c|c|c|}
\hline \multirow[t]{2}{*}{ Variable } & \multicolumn{2}{|c|}{ AEFI reports } & \multirow{2}{*}{$\begin{array}{l}\text { AEFI per } 100000 \text { total } \\
\text { population }^{\mathrm{a}}\end{array}$} & \multirow{2}{*}{$\begin{array}{l}\text { No. of doses } \\
\text { given }\end{array}$} & \multirow{2}{*}{$\begin{array}{c}\text { AEFI per } \\
100000 \text { doses }\end{array}$} & \multirow[t]{2}{*}{ RR (95\% CI) } \\
\hline & No. & $\%$ & & & & \\
\hline \multicolumn{7}{|l|}{ Age (years) } \\
\hline$<1$ & 657 & 73.8 & - & 7054330 & 9.3 & $1.5(1.3-1.7)^{*}$ \\
\hline $1-2$ & 127 & 14.3 & - & 2508683 & 5.1 & $0.6(0.5-0.7)$ \\
\hline$>2$ & 106 & 11.9 & - & 1186000 & 8.9 & $1.1(0.9-1.3)$ \\
\hline \multicolumn{7}{|l|}{ Sex } \\
\hline Male & 453 & 50.9 & 17.5 & 6214805 & 7.3 & $0.8(0.7-0.9)$ \\
\hline Female & 437 & 49.1 & 30.9 & 4534208 & 9.6 & $1.3(1.2-1.5)^{*}$ \\
\hline \multicolumn{7}{|l|}{ Governorate } \\
\hline Musandam & 8 & 0.9 & 20.1 & 110086 & 7.3 & $0.9(0.4-1.7)$ \\
\hline North Sharqiyah & 65 & 7.3 & 26.8 & 804333 & 8.1 & $0.9(0.7-1.2)$ \\
\hline Dakhliyah & 146 & 16.4 & 36.2 & 1601241 & 9.1 & $1.1(0.9-1.3)$ \\
\hline Dhahira & 52 & 5.8 & 28.0 & 598216 & 8.7 & $1.0(0.8-1.4)$ \\
\hline Buraimi & 48 & 5.4 & 48.1 & 247785 & 19.4 & $2.4(1.7-3.2)^{*}$ \\
\hline Wustah & 7 & 0.8 & 17.1 & 88364 & 7.9 & $0.9(0.4-2.0)$ \\
\hline North Batinah & 123 & 13.8 & 18.8 & 1953813 & 6.3 & $0.7(0.6-0.8)$ \\
\hline Dhofar & 33 & 3.7 & 8.7 & 926244 & 3.7 & $0.4(0.3-0.6)$ \\
\hline South Batinah & 144 & 16.2 & 39.9 & 1153254 & 12.5 & $1.6(1.3-1.9)^{*}$ \\
\hline Muscat & 214 & 24.0 & 17.7 & 2161808 & 9.9 & $1.2(1.0-1.4)^{*}$ \\
\hline South Sharqiyah & 50 & 5.6 & 18.7 & 1103869 & 4.5 & $0.5(0.4-0.7)$ \\
\hline Total & 890 & 100 & 21.4 & 10749013 & 8.3 & Reference (-) \\
\hline
\end{tabular}

${ }^{*} \mathrm{P}<0.05$.

${ }^{a_{2}} 2014-2015$ population estimate.

$\mathrm{R} R=$ relative risk, $C I=$ confidence interval

Buraimi (19.4/100 ooo doses; $\mathrm{RR}=2.4$, 95\% CI: 1.7-3.2, $\mathrm{P}<$ 0.001), South Batinah (12.5/100 ooo doses; $R R=1.6,95 \% \mathrm{CI}$ : 1.3-1.9, $P<0.001$ ) and Muscat (9.9/100 ooo doses; $R R=1.2$, 95\% CI: 1.0-1.4, P 0.001) (Table 1).

Table 2 shows the number of AEFI reports by type of reaction for the period 2006-2015. The most common adverse events were local reactions such as severe pain and/or swelling, accounting for $48.9 \%$ (435/890) of the reports over the 10 -year review period, followed by BCG adenitis, accounting for $23.7 \%$ (211/890). Injection abscess was reported in $8.4 \%(75 / 890)$ of AEFI. However, the doserelated rates for all doses given showed that the 2 most commonly reported adverse reactions were BCG adenitis (31.1/100 ooo doses) and local reactions (4.1/100 000). The more serious reactions were rarer - systemic reactions (0.8/100 000 doses) and injection abscess (0.7/100 000 doses). BCG adenitis was a significantly more common event after vaccination compared with adverse events following other vaccines $(\mathrm{RR}=4.6,95 \% \mathrm{CI}$ : 3.9-5.4, $\mathrm{P}<$ 0.001).

Table 3 shows the distribution and rate of common AEFI according to the vaccine administered and type of reaction. Pentavalent vaccine was responsible for the highest number of AEFI reports $(267,30.0 \%)$, followed by BCG $(257,28.9 \%)$ and DTP $(154,17.3 \%)$. Although there were more adverse events associated with pentavalent and
DTP vaccines, a majority of them were local minor events. For DTP, local reactions, injection abscess and systemic reactions occurred in $83.1 \%, 7.8 \%$ and $4.5 \%$ of reactions respectively. For the pentavalent vaccine, $73.8 \%$ of the events were local reactions and 5.6\% systemic reactions. The adverse events due to Hexa vaccine were much lower, 0.8 per 100 ooo Hexa doses administered, with only local reactions reported and no serious or systemic events. For the MMR vaccine, $17 \%$ were systemic reactions, however, influenza vaccine had the highest proportion of systemic reactions (66\%). The rate of $\mathrm{BCG}$ injection abscess was $7.4 \%$ or 2.8 per 100000 BCG doses administered.

A total of $49 / 890(5.5 \%)$ serious adverse events were reported, the majority of which were from the Penta vaccine (65.3\%). The serious events included convulsions (26 cases), febrile convulsions (19 cases), anaphylactic reactions (1 case), and giddiness and temporary loss of consciousness (3 cases).

The BCG vaccine resulted in more adverse events per doses given (37.9/100 ooo doses) mostly due to adenitis (82.1\%). The rates were more or less similar for Penta and DTP vaccines, 15.1 and 11.5 per 100000 administered respectively. There were 24 reports for the PCV (2.7 per 100000 PCV doses administered) and 18 reports for the IPV (1.6 per 100000 IPV doses administered) during the period of these vaccines' use (2009-2015). There 


\begin{tabular}{|c|c|c|c|}
\hline \multirow[t]{2}{*}{ Type of AEFI } & \multicolumn{2}{|c|}{ AEFI reports } & \multirow[t]{2}{*}{ AEFI per 100000 doses $^{a}$} \\
\hline & No. & $\%$ & \\
\hline Adenitis (BCG) & 211 & 23.7 & 31.1 \\
\hline Local reactions & 435 & 48.9 & 4.1 \\
\hline Systemic reactions & 76 & 8.5 & 0.7 \\
\hline Injection abscess & 75 & 8.4 & 0.7 \\
\hline Central nervous system & 50 & 5.6 & 0.5 \\
\hline Allergic reaction & 37 & 4.2 & 0.3 \\
\hline Other reactions & 6 & 0.7 & 0.1 \\
\hline Total & 890 & 100.0 & 8.3 \\
\hline
\end{tabular}

${ }^{a}$ Total doses given were 10749013 except for BCG with 678071 doses.

$B C G=$ Bacille Calmette-Guérin .

were 47 reports for MMR (3.6 per 100000 MMR doses administered) and 12 for HBV (o.6 per $100000 \mathrm{HBV}$ doses) (Table 4).

\section{Discussion}

This paper is the continuation of our efforts to provide an overview of all reported AEFI during the period 20062015. In Oman, the Ministry of Health policy dictates mandatory notification of all vaccine-related adverse events within 24 hours (4). AEFI surveillance is complex because the association between the reported exposure(s) and outcome(s) is temporal but not always causal. Inadequate or misleading information may have an adverse effect on the analysis and interpretation of AEFI surveillance data. Identification, detection, prevention and appropriate reporting of AEFI are therefore essential to ensuring the safety of vaccinations.

We received 890 reports during 2006-2015, out of over 10 million doses of vaccines that were administered. The overall rate of AEFI for the 14 reported vaccine types was 8.3 per 100000 doses administered, which is comparable to the rates (10.8/100 000 doses) in the previous decade (1996-2005) in Oman (5). Our overall reporting rates are comparable with Zhejiang province, China, which reported 9.2 AEFI per 100000 doses during 2008-2011 (8). Higher rates were reported from the United States of America (USA), Australia and Canada. The USA reported a rate of 11.4 per 100000 doses and Australia 13.9 per 100000 doses $(9,10)$. Canada reports varied from 14.8 to 10.1 per 100000 doses in 2005 and 2012 respectively (11).

\begin{tabular}{|c|c|c|c|c|c|c|c|c|c|c|}
\hline \multirow{2}{*}{$\begin{array}{l}\text { Type of } \\
\text { vaccine }\end{array}$} & \multirow{2}{*}{$\begin{array}{l}\text { Total no. } \\
\text { of AEFI } \\
\text { reports }\end{array}$} & \multicolumn{3}{|c|}{ Systemic reactions } & \multicolumn{3}{|c|}{ Local reactions } & \multicolumn{3}{|c|}{ Injection abscesses } \\
\hline & & No. & $\%$ & Rate $^{a}$ & No. & $\%$ & Rate $^{\mathrm{a}}$ & No. & $\%$ & Rate $^{a}$ \\
\hline BCG & 257 & 1 & 0.4 & 0.1 & 24 & 9.3 & 3.5 & 19 & 7.4 & 2.8 \\
\hline DTP & 154 & 7 & 4.5 & 0.5 & 128 & 83.1 & 9.6 & 12 & 7.8 & 0.9 \\
\hline Penta & 267 & 15 & 5.6 & 0.9 & 197 & 73.8 & 11.2 & 23 & 8.6 & 1.3 \\
\hline $\mathrm{HBV}$ & 12 & 3 & 25.0 & 0.1 & 8 & 66.7 & 0.4 & 1 & 8.3 & 0.1 \\
\hline MMR & 47 & 8 & 17.0 & 0.6 & 11 & 23.4 & 0.8 & 4 & 8.5 & 0.3 \\
\hline Hexa & 2 & 0 & - & - & 2 & 100 & 0.8 & 0 & - & - \\
\hline IPV & 18 & 2 & 11.1 & 0.3 & 5 & 27.8 & 0.7 & 1 & 5.6 & 0.1 \\
\hline $\operatorname{PCV} 7,10,13$ & 24 & 7 & 29.2 & 0.5 & 16 & 66.7 & 1.0 & 3 & 12.5 & - \\
\hline Varicella & 1 & 1 & 100 & 0.3 & 0 & - & - & 0 & - & - \\
\hline Influenza & 47 & 31 & 66 & - & 8 & 17.0 & - & 6 & 12.8 & - \\
\hline DT & 10 & 1 & 10 & - & 6 & 60.0 & - & 2 & 20.0 & - \\
\hline $\mathrm{TT}$ & 44 & 0 & - & - & 26 & 59.1 & - & 2 & 4.5 & - \\
\hline $\mathrm{Td}$ & 7 & 0 & - & - & 4 & 57.1 & - & 2 & 28.6 & - \\
\hline Total & 890 & 76 & - & - & 435 & - & - & 75 & - & - \\
\hline
\end{tabular}

aPer 100000 doses of particular vaccine given.

The table includes events related to systemic and local reactions, and injection abscesses only; therefore the total does not correspond to the total no. of AEFI reports (89o).

$B C G=$ bacille Calmette-Guérin, DTP = diphtheria-tetanus-pertussis, Penta $=$ DTP-Hib-HBV, HBV = hepatitis B virus, MMR = measles-mumps-rubella, Hexa $=I P V-D T P-H i b-H B V, P C V=$ pneumococcal conjugate vaccine, IPV = inactivated polio vaccine. 


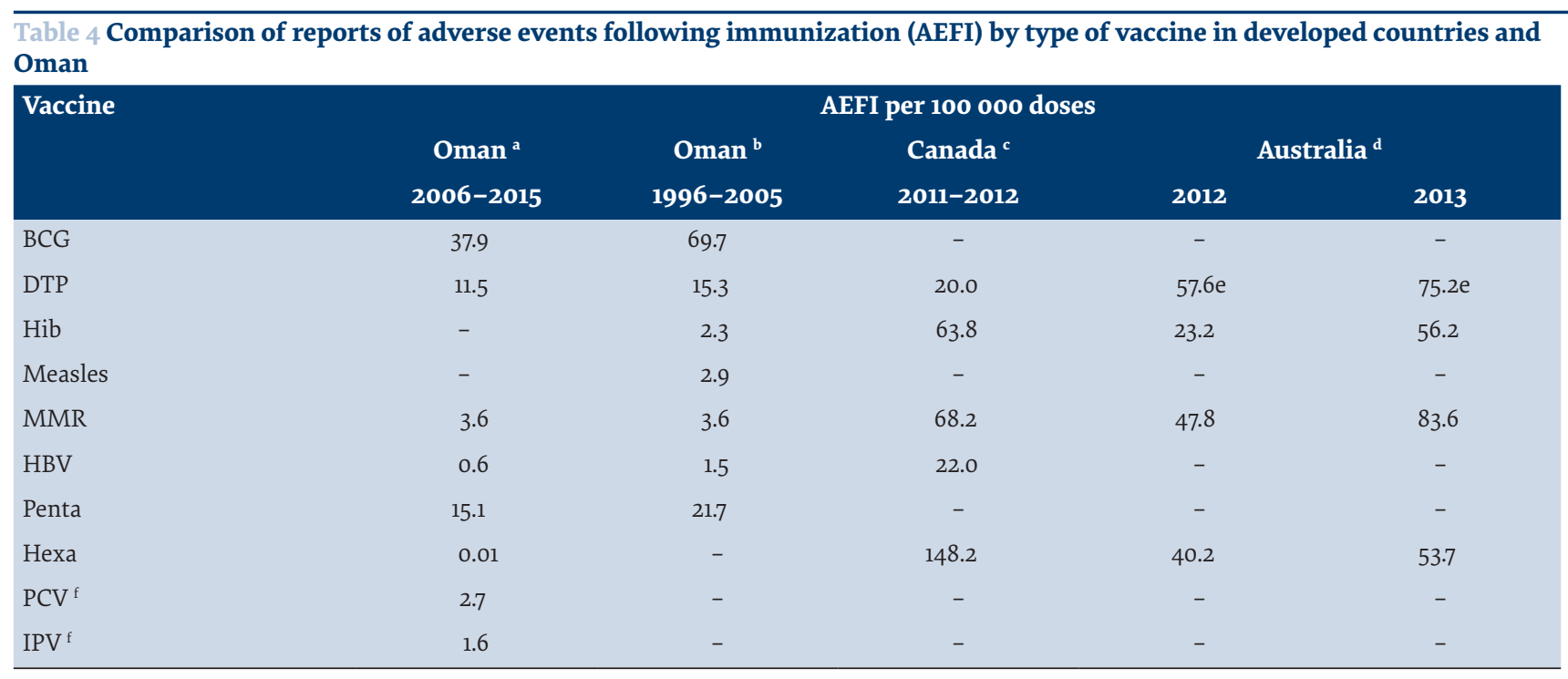

Sources: ${ }^{a}$ Current study $,{ }^{b}(5),{ }^{c}(11),{ }^{d}(10)$.

eDTPa.

f2009-2015.

$(-)=$ No study data available.

BCG = bacille Calmette-Guérin, DTP = diphtheria-tetanus-pertussis, Hib = Haemophilus influenzae type B, MMR = measles-mumps-rubella, HBV = hepatitis B virus, Penta = DTP-Hib-HBV, Hexa = IPV-DTP-Hib-HBV, PCV = pneumococcal conjugate vaccine, IPV = inactivated polio vaccine.

The AEFI reporting rates ranged from 5.4 to 12.3 per 100000 doses during the study period. The highest rates were observed in 2007 and 2013, while the lowest was in 2012 (Figure 1). In 2006, we noted there was underreporting of AEFI, hence an awareness campaign was conducted during 2007 which led to improved reporting and the higher rate seen in 2007. Another reason for the higher rate in 2007 could be the introduction of MMR as a second dose that year. The higher rate of 11.2 per 100000 doses in 2013 followed the introduction of the MMR vaccine among post-partum women and the vaccination of certain high-risk groups, including all health care workers. A continuing periodic staff training programme resulted in a decrease in the AEFI subsequently.

Under-reporting can be factor in passive reporting systems (12). Although the AEFI in Oman is largely a passive system, active surveillance was also undertaken during rumour verification, $\mathrm{H} 1 \mathrm{~N} 1$ vaccination and health care worker vaccination campaigns to prevent under-

Figure 1 Trend in adverse events following immunization (AEFI) in Oman, 2006-2015

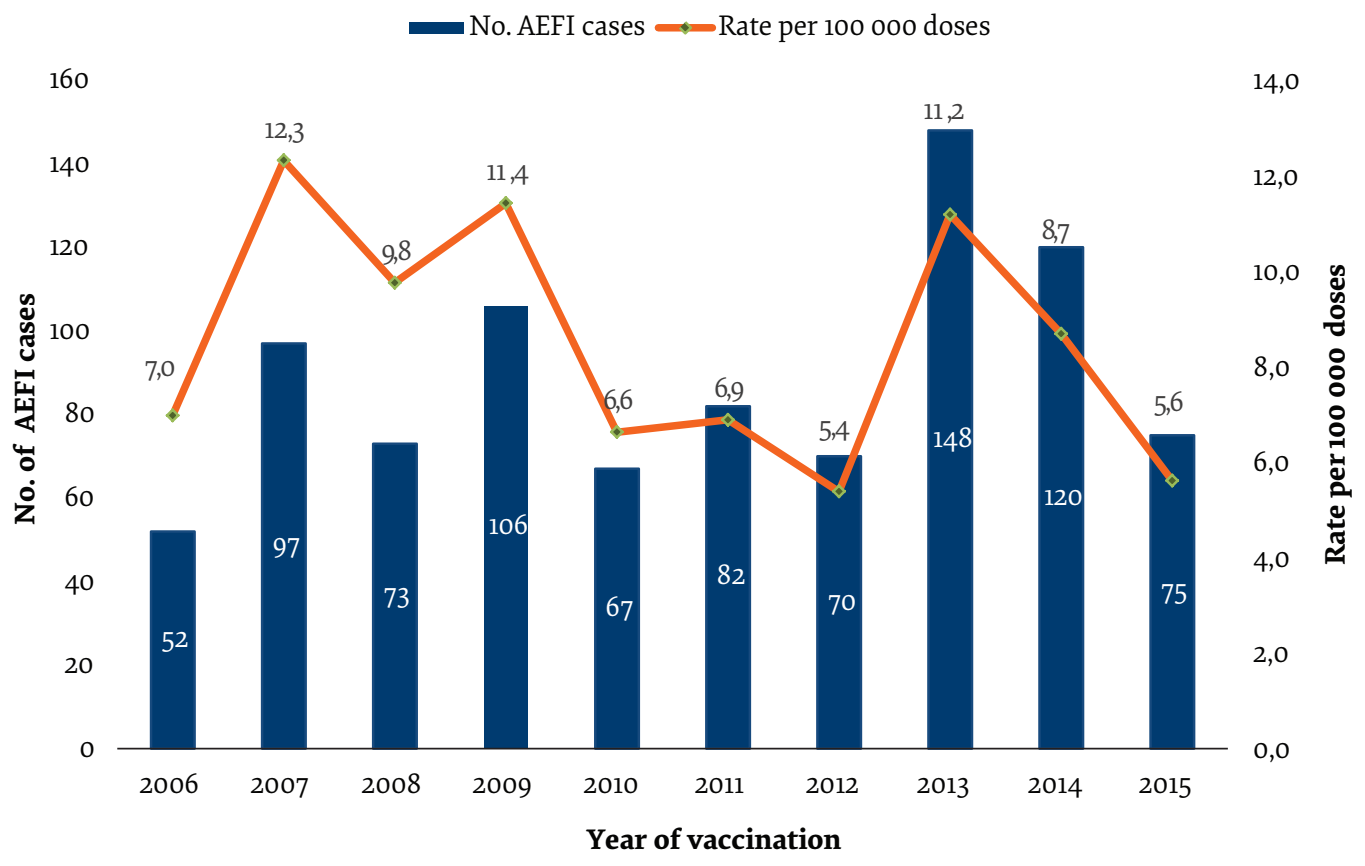


reporting.

The number of adverse events in females was significantly higher than in males. Other studies have reported more events in females, while others have reported only minimal differences between the sexes. Females typically develop higher antibody responses and experience more adverse reactions following vaccination than males $(9,11,13)$.

The highest proportion of AEFI reports was among children aged $<1$ year $(73.8 \%)$, which reflects the fact that this is the age group receiving the greatest numbers of vaccines. These proportions were lower in other countries, which suggests that in these countries the target age group is generally adults and these variations in rates between countries may be largely due to the use of different vaccines and regimens $(10,11)$. In our study, the dose-related rates were significantly higher among children aged $<1$ year compared with those aged 1-2 and $>2$ years in our study $(R R=1.5,95 \% C I$ : $1.3-1.7)$, which may be related to the immune response to vaccines in different age groups. A report from Canada showed that the age group 1-2 years had more serious events when compared with other age groups (11).

Comparable to reports from the USA, Australia and Canada, the AEFI reporting rates varied between different provinces in Oman (9-11). Provincial variations exist for several reasons that may not be related to actual safety issues. These include variations in vaccination delivery (public or private), reporting rates, staff motivation and special vaccination programmes.

A rate of over 10 AEFI per 100000 doses was found for 3 years in our study. In 2009, the higher rate could be explained by the active surveillance of the $\mathrm{H1N} 1$ vaccination campaign and in 2013, it was a result of strengthening active surveillance of adverse events among vaccinated health care workers.

The most common adverse events were local reactions (48.8\%), such as injection-site hypersensitivity or oedema, rash and vasodilatation. Similarly, in Australia and Canada the most commonly reported adverse events were local reactions $(10,11)$. In contrast, the rate of serious adverse events was lower (5.5\%) compared with data from the USA in 2003 (14.2\%) (9). Two other studies from Australia found rates of serious reactions of $1 \%$ and $9 \%$ of all reactions respectively $(14,15)$.

Pentavalent and DTP vaccines were most commonly associated with adverse events. There were 267 and 154 reports respectively (2.5 and 1.4 per 100000 doses administered) during the 2006-2015 period. An Australian AEFI study reported similarly higher rates for these vaccines compared with other vaccines, 46.3 and 46.6 per 100000 population respectively (15). A report from China also showed higher proportion of adverse events for DPT vaccine (30\%) (8). Adverse events due to BCG (37.9 per 100 ooo doses) were at the lower end of expected rates (100-1 000 per million doses) (16). A Swedish study reported a higher rate of 1.9 per 1000 doses of $B C G$ vaccine administered (17). The rate of BCG injection abscess in our study was 31.1 per 100 ooo doses administered which is lower than a study in Sweden, which reported 1.4 injection abscesses per 1000 vaccinated children (17).

Serious adverse events are uncommon with Hexa vaccines (16), and in our study this vaccine produced fewer local/systemic reactions than other vaccines. Overall and serious adverse events have been considerably reduced as a result of the use of the Hexa instead of the Penta vaccine, probably because of the acellular pertussis component (18). In specific situations, e.g. the clustering of AEFI events following MR vaccination observed in October 1995, a detailed epidemiological investigation was conducted (19). A serious adverse event following DTP vaccine administration in the year 2000 was also thoroughly investigated (20). Thereafter, there has been no clustering of adverse events to date.

Convulsions are usually associated with the DTP vaccine. In our study, convulsions occurred in 4 per 10000 doses and anaphylaxis in only 1 case. However, a report from WHO on vaccine safety showed that convulsions accounted for 1 in 12500 doses administered with the DTP vaccine (16).

Table 4 compares the overall rates of AEFI for the different vaccines reported in other countries and in the previous study in Oman with the present study. The overall AEFI rates during the current study period 2006-2015 were lower compared with the previous years in Oman and also in other countries for all the reported vaccines. The variation in the AEFI rates could be due to different standards in the AEFI reporting systems of different countries. The comparison of the Omani AEFI data with other studies around the world should be interpreted with caution since the vaccines administered, immunization programmes, AEFI reporting system and presentation of data may vary considerably.

Limitations of this study include the use of retrospective, passive surveillance data which may result in under-reporting. Further operational research could be undertaken to identify and address the specific risk factors of AEFI.

\section{Conclusions}

In Oman, AEFI reported rates are similar to or below international averages. Surveillance of AEFI is always an integral component of a national immunization programme. As with any passive surveillance systems, under-reporting is likely. Continued efforts on the part of immunization service providers and public health practitioners are essential to strengthen and sustain the quality of AEFI surveillance in Oman. Addressing vaccine safety issues effectively preserves the integrity of the immunization programme and avoids undue concerns in the community. 


\section{Acknowledgements}

We are grateful to all the doctors, immunization staff and governorate immunization supervisors involved in the reporting of the adverse events, without whom this analysis would not have been possible.

\section{Funding: None.}

Competing interests: None declared.

\section{Surveillance des manifestations postvaccinales indésirables à Oman, 2006-2015}

\section{Résumé}

Contexte : En 1996, Oman a lancé son programme de surveillance des manifestations postvaccinales indésirables (MAPI) afin de répondre aux préoccupations sur la sécurité des vaccins. En 2010, une analyse des activités de surveillance des MAPI a été menée sur une période de 10 ans (1996-2005).

Objectifs : La présente étude avait pour objectif principal de décrire la tendance de la surveillance des MAPI sur une période de 10 ans (2006-2015) et de comparer les résultats obtenus avec un rapport produit antérieurement à Oman ainsi que des rapports provenant d'autres pays.

Méthodes : Un examen descriptif des MAPI basé sur les dossiers médicaux de patients a été réalisé à l'aide de la base de données nationale de la surveillance des MAPI sur la période de l'étude (2006-2015).

Résultats : Au total, 890 rapports de manifestations indésirables ont été reçus, correspondant à un taux de 21,4 pour 100000 personnes, soit 8,3 pour 100000 doses administrées sur la période de l'examen. Les MAPI les plus fréquemment rapportées étaient l'adénite à BCG et les réactions locales - 31,1 et 4,1 pour 100000 doses respectivement. Il n'y avait pas de cas rapportés de décès. Le vaccin pentavalent était responsable de la plus grande proportion de manifestations indésirables $(30 \%)$. Les réactions locales étaient la manifestation indésirable la plus courante parmi tous les vaccins administrés. Le vaccin hexavalent était à l'origine de moins de manifestations indésirables que le vaccin pentavalent, probablement du fait du composant anticoquelucheux acellulaire - 0,8 contre 1,5 pour 100000 doses administrées respectivement.

Conclusion : Le taux global de MAPI (8,3 pour 100000 doses administrées) est comparable au taux (10,8/100 000 doses) de la décennie précédente (1996-2005) à Oman. Les taux rapportés pour les vaccins individuels sont similaires ou inférieurs aux taux internationaux.

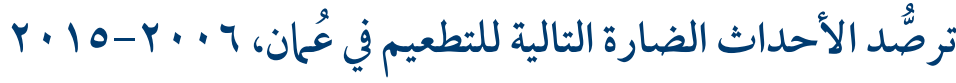

$$
\begin{aligned}
& \text { براكاش باتل، بدر الرواحي، عذاري الجواري، إدريس العبيداني، سيف العبري }
\end{aligned}
$$

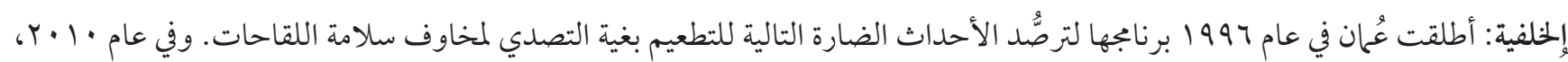

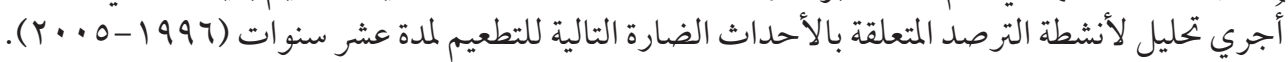

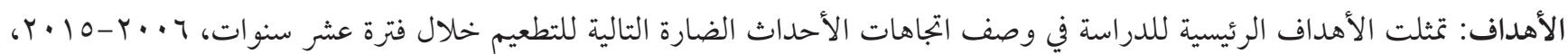

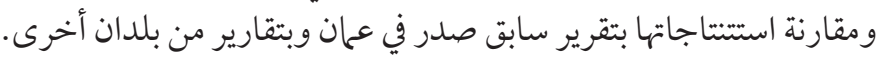

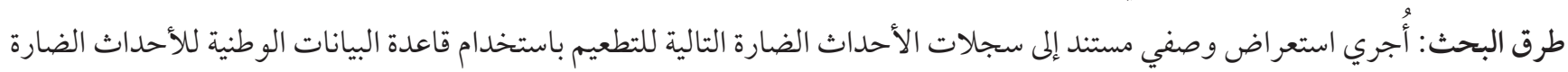

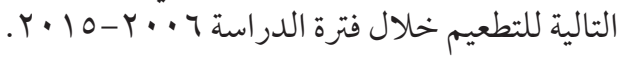

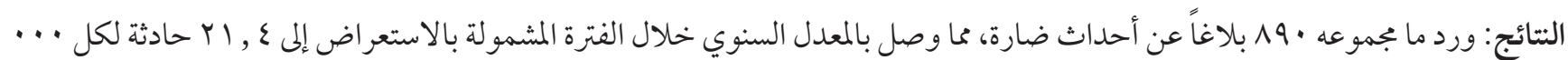

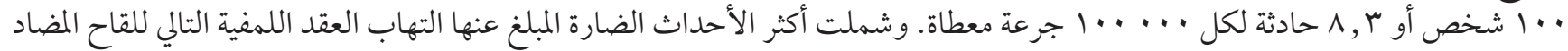

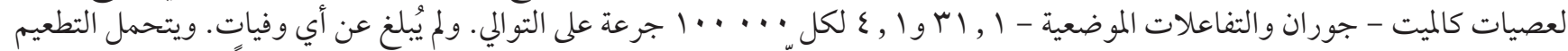

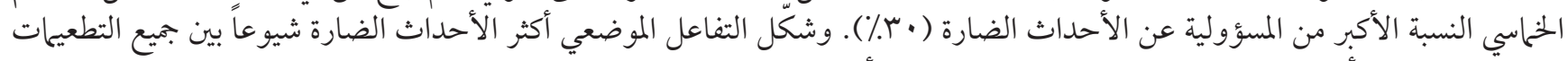

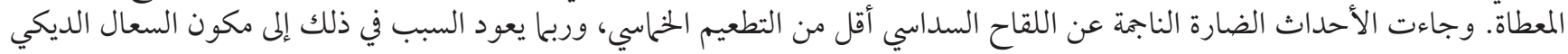

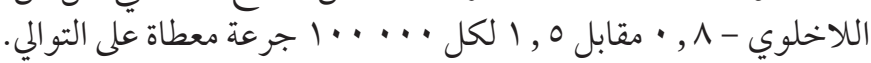

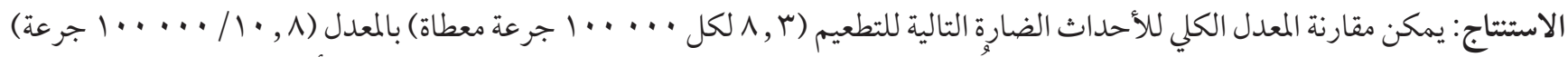

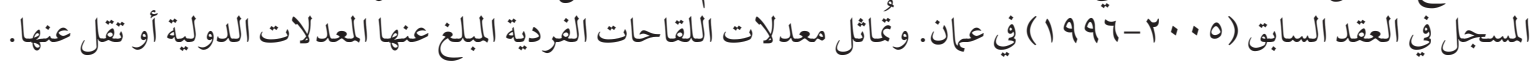




\section{References}

1. World Health Organization. Global Vaccine Safety. Adverse events following immunization (AEFI) [webpage] (http://www.who. int/vaccine_safety/initiative/detection/AEFI/en/, accessed 14 November 2017).

2. Global status of immunization safety: a report based on the WHO/UNICEF Joint Reporting Form. Wkly Epidemiol Rec. 2003 Feb 14;78(7):42-7. PMID:12621927

3. Global Advisory Committee on Vaccine Safety, June 2012. Wkly Epidemiol Rec. 2012 Jul 27;87(30):281-7. PMID:22905369

4. The milestones of EPI in Oman. Manual on the Expanded Program on Immunization. 3rd ed. Muscat: Ministry of Health; 2003:1-62 (http://www.cdscoman.org/uploads/cdscoman/EPI_Manual.pdf, accessed 14 November 2017).

5. Al Awaidy S, Bawikar S, Prakash KR, Al Rawahi B, Mohammed AJ. Surveillance of adverse events following immunization: 10 years' experience in Oman. East Mediterr Health J. 2010 May;16(5):474-80. PMID:20799545

6. Surveillance of adverse events following immunization, field guide for managers of immunization programmes. Geneva: World Health Organization; 1997.

7. Mansoor O, Shin S, Maher C and the Immunization Focus of WPRO. Immunization safety surveillance: Guidelines for managers of immunization programmes on reporting and investigating adverse events following immunization. Manila: World Health Organization Regional Office for the Western Pacific; 1999.

8. Hu Y, Li Q, Lin L, Chen E, Chen Y, Qi X. Surveillance for adverse events following immunization from 2008 to 2011 in Zhejiang Province, China. Clin Vaccine Immunol. 2013 Feb;20(2):211-7. http://dx.doi.org/10.1128/CVI.00541-12 PMID:23239804

9. Zhou W, Pool V, Iskander JK, English-Bullard R, Ball R, Wise RP, et al. Surveillance for safety after immunization: Vaccine Adverse Event Reporting System (VAERS) -United States, 1991-2001. MMWR Surveill Summ. 2003 Jan 24;52(1):1-24. PMID:12825543

10. Mahajan D, Dey A, Cook J, Harvey B, Menzies R, Macartney K. Surveillance of adverse events following immunisation in Australia annual report, 2013. Commun Dis Intell Q Rep. 2015 09 30;39(3):E369-86. PMID:26620351

11. Law BJ, Laflèche J, Ahmadipour N, Anyoti H. Canadian Adverse Events Following Immunization Surveillance System (CAEFISS): Annual report for vaccines administered in 2012. CCDR. 2014 December 4;40:S-3.

12. Stratton KR, Howe CJ, Johnston RB. Research strategies for assessing adverse events associated with vaccines: a workshop summary. Washington: National Academy Press; 1994.

13. Sabra LK, Ian M, Eleanor NF. Sex-based differences in immune function and responses to vaccination. Trans R Soc Trop Med Hyg. 2015 Jan;109(1):9-15. http://dx.doi.org/10.1093/trstmh/tru167 PMID:25573105

14. Lawrence GL, Boyd I, McIntyre PB, Isaacs D. Surveillance of adverse events following immunization in Australia 2004. Commun Dis Intell Q Rep. 2005;29(3):248-62. PMID:16220860.

15. Lawrence G, Boyd I. Supplementary report: surveillance of adverse events following immunisation among children aged $<7$ years in Australia, 1 January to 30 June 2006. Commun Dis Intell Q Rep. 2006;30(4):438-42. PMID:17330385

16. Supplementary information on vaccine safety, Part 2: Background rates of adverse events following immunization. Geneva: World Health Organization; 2000.

17. Romanus V, Fasth A, Tordai P, Wiholm BE. Adverse reactions in healthy and immunocompromised children under six years of age vaccinated with the Danish BCG vaccine, strain Copenhagen 1331: implications for the vaccination policy in Sweden. Acta Paediatr. 1993 Dec;82(12):1043-52. PMID:8155923

18. Centres for Disease Control and Prevention (CDC). Pertussis vaccination: use of acellular pertussis vaccines among infants and young children. Recommendations of the Advisory Committee on Immunization Practices (ACIP). Morbidity and mortality weekly report. 1997;46 RR-7:1-25. PMID:9011775

19. Ministry of Health, Oman. Hypersensitivity reactions reported with MR vaccine. Community Health and Disease Surveillance Newsletter. 1995;4(3):7-8.

20. Ministry of Health, Oman. An unusual presentation of AEFI. Community health and disease surveillance newsletter. $2000 ; 9(1): 10$. 